\title{
TECNOLOGIAS INDÍGENAS DA PERSPECTIVA DE PESQUISADORES INDÍGENAS ${ }^{1}$
}

\author{
$\mathrm{CARON}^{2}$, Mônica Filomena \\ Universidade Federal de São Carlos - Campus Sorocaba \\ (UFSCAR) \\ $\mathrm{KALAPALO}^{3}$, Jeika \\ Universidade Federal de São Carlos - Campus Sorocaba \\ (UFSCAR) \\ SANTOS ${ }^{4}$, Geovan José dos \\ Universidade Federal do Paraná (UFPR)
}

\section{RESUMO}

O propósito deste estudo é coletar e reunir dados e conhecimentos de alunos indígenas sobre as tecnologias presentes em seus cotidianos e coletivos. Trata-se, portanto, de estudar fenômenos culturais no seu modo físico de apresentação, mas também e sobretudo através das ideias trazidas e elaboradas pelos alunos. Trata-se, também, da descrição das atividades segundo as narrativas trazidas sobre os processos de desenvolvimento das tecnologias presentes e identificadas nas práticas diárias nas aldeias e nos costumes de seus povos. Realiza-se uma breve visita sobre alguns documentos da literatura nacional e internacional sobre as tecnologias indígenas, com maior detalhamento do panorama encontrado no Brasil.

Palavras-chave: Tecnologias Indígenas. Patrimônio Material. Saberes Indígenas.

1 Estudo realizado com o Apoio financeiro do MEC, ProEx/UFSCar.

2 Docente no Departamento de Geografia, Turismo e Humanidades (DGTH).

3 Discente do Curso de Administração da UFSCAR - Campus Sorocaba, etnia Kalapalo, aldeia Aiha. E-mail: j.klp@hotmail.com.

4 Discente do Curso de Direito da UFPE, etnia Pankararu. E-mail: ferrgeov@ hotmail.com. 


\begin{abstract}
The purpose of this study is to collect and gather data and knowledge of indigenous students about the technologies present in their daily and collective. Therefore, it is a question of studying cultural phenomena in their physical presentation, but also and especially through the ideas brought and elaborated by the students. It is also a description of the activities according to the narratives brought about the processes of development of the technologies present and identified in the daily practices in the villages and in the customs of their peoples. A brief visit is made to some documents of the national and international literature on indigenous technologies, with a more detailed view of the panorama found in Brazil.
\end{abstract}

Key words: Indigenous technologies. Material patrimony. Indigenous knowledge.

\title{
INTRODUÇÃO
}

Os espaços acadêmicos multiculturais são ricos em saberes e práticas. A tradução que pode ser feita nesses espaços é uma tradução cultural, entre culturas distintas, pois muito conhecimento pode ser compartilhado e cabe a cada cultura decidir quando compartilhar, o que compartilhar, como compartilhar e se é desejável compartilhar (SANTOS, 2005, 2011).

O propósito desse estudo é coletar e reunir dados e conhecimentos de alunos indígenas sobre as tecnologias presentes em seus cotidianos e coletivos. Trata-se, portanto, de estudar fenômenos culturais no seu modo físico de apresentação através das ideias trazidas e elaboradas pelos alunos; em um segundo momento, tratar-se-á da descrição das narrativas trazidas sobre os processos de desenvolvimento das tecnologias presentes em suas realidades. Pretende-se, em continuidade ao presente panorama, sobretudo empírico, realizar uma breve revisão de documentos e da literatura nacional (e eventualmente internacional) sobre a tecnologia indígena e suas presenças (ou não) nas universidades, mas com foco no panorama nacional.

Para Veraszto (2008) as palavras 'técnica' e 'tecnologia' têm origem comum na palavra grega techné ("arte, saber fazer ou ofício") - utilizada para definir os conhecimentos que permitem fabricar objetos e modificar o meio ambiente, com a finalidade de 
satisfazer as necessidades humanas - e na palavra logus ("conjunto de saberes, razão"). Portanto, estudar tecnologia significa estudar a razão do saber fazer, o estudo da própria atividade do modificar, do transformar, do agir. A técnica, como um fluxo de elementos, em contraposição à teoria que busca explicar como a coisa é. A tecnologia envolve instrumentos, necessidades, aprimoramento e reformulação e desenvolvimento.

O interesse e o fascínio pelas tecnologias sempre foi e é inerente ao ser humano, independentemente de sua etnia, grau de conhecimento ou condições econômicas. A sua presença é marcada desde a pré-história e na atualidade tem-se dado importância menor às técnicas tradicionais e saberes dos povos nativos e as tecnologias modernas são vistas como único meio para as "soluções dos problemas humanos".

A princípio perguntamo-nos: qual seria a noção de 'Tecnologias Indígenas' da comunidade acadêmica? Saberia da existência de amplo conjunto de técnicas tradicionais entre os povos indígenas, envolvendo inúmeras esferas de ação humana?

Pretendeu-se, então, realizar uma revisão de documentos e de literatura nacional e internacional sobre a tecnologia indígena nas universidades, e a leitura de Ribeiro (1986) frente à natureza tecnológica desenvolvida pelos povos indígenas, em que se observam os fenômenos culturais nas distintas modalidades: das ideias, do comportamento e dos objetos físicos (NEWTON, 1986). Os objetos frutos de modelagens específicas de cada cultura indígena caracterizam suas particularidades de expressão e também atuam nas identidades culturais. Nesse sentido, as Tecnologias Indígenas ultrapassam o aspecto de matéria cultural e passam a representar um duplo sentido: material e imaterial.

Em um segundo momento do trabalho pretendeu-se produzir a descrição de atividades pelos alunos indígenas segundo as narrativas trazidas sobre seus processos de desenvolvimento, apresentadas no presente texto.

Com esse trabalho pretendeu-se, também, contribuir para o debate sobre os direitos indígenas e seus valores intrínsecos à contemporaneidade, refletindo sobre as formas como seus saberes culturais materiais e imateriais aparecem (se aparecem) nas políticas públicas destinadas aos povos indígenas; e as formas como os direitos indígenas são regidos nos documentos estatais que regulam o acesso e a proteção dos patrimônios materiais e outros bens tradicionais. 
O tema demanda uma abordagem teórica e metodológica que atente para os direitos indígenas, considerando as assimetrias envolvidas e os processos de imposição das normas estatais aos grupos etnicamente diferenciados. As mesmas variações encontramos nas escolas indígenas, pois, de acordo com Grupioni (2008), foi a partir da década de 80 do século XX que a escola passou a ser disponibilizada entre a maioria dos diferentes grupos indígenas. Em tese defendida no âmbito dos estudos da antropologia, o autor analisa o processo pelo qual se constituiu a proposta de educação diferenciada como um direito dos grupos indígenas no Brasil.

\section{Dados e resultados encontrados}

Como previsto no trabalho, iniciamos um debate com o grupo de alunos para detectarmos a presença de tecnologias em seus cotidianos.

Em um dos relatos, de aluno da etnia Kalapalo, temos que foi, a partir da década de 40 do século XX, com a chegada dos irmãos Orlando Villas-Bôas nas aldeias, que teve início naquele contexto a presença da tecnologia da informação. A chegada de novas ferramentas ajudou os Kalapalo: na fabricação de canoas e no uso de madeiras mais resistentes e duradouras, acelerando os trabalhos, com efeitos semelhantes nas roças, possibilitando a derrubada de árvores e a abertura mais rápida de novos roçados; na pesca, com a chegada de novas linhas e de redes, que possibilitaram novas técnicas antes indisponíveis no uso da flecha, da lança e do cipó. Mas, através das leituras realizadas para esse trabalho, JK também observa que a tecnologia esteve presente sempre nas seguintes atividades: agricultura, uso da água e do fogo, construção das casas (ocas) e canoas, cuidados da saúde (raizeiro), no uso de materiais que não agredissem a natureza e contribuíssem para o equilíbrio ecológico, nas roças.

JK também observa que entre as etnias do Xingu a aprendizagem de tecnologias ocorre através da observação dos hábitos dos adultos pelas crianças, que os acompanham na confecção de canoas, ocas, na roça e na pesca; e na elaboração de artesanatos, para os quais os Kalapalo usam caracóis (outras etnias não usam o mesmo material, então realizam trocas inter-tribais). As mulheres também ensinam suas filhas a confeccionar esteiras de fio de buriti e redes para dormir. 
Em relato de outro aluno que participou do presente trabalho, GP, da etnia Pankararu, de Pernambuco, traz a seguinte narrativa: a etnia usava, na confecção de roupões, o caroá, bromélia cujo nome científico é Neoglasiovia variegata, também conhecida como gravatá, gravá, caruá, croatá, caraguatá e coroatá, e, de acordo com o Instituto Sociedade, População e Natureza (2016),

é um tipo de bromélia de poucas folhas, com flores vermelhas ou rosadas. Seu nome vem da palavra em tupi kara wã, que significa talo com espinho. É uma planta resistente e típica das áreas de caatinga. As folhas do caroá fornecem fibra para a confecção de barbantes, linhas de pesca, tecidos, cestos, esteiras e chapéus, além de outras peças artesanais e decorativas.

Segundo relato de GP a espécie entrou em extinção pela falta de chuva, o que fez com que os Pankararu fossem em busca de alternativas fazendo uso de GPS (Global Positioning System) para mapeamento dos lugares onde se encontravam outras bromélias e investigando sobre os modos de protegê-las. O uso de tecnologia novas pode ter ajudado também na hora de construir lagos, tanques e na piscicultura.

Em seu texto sobre os Asurini no Xingu, SILVA (2013) observa que entre 2003 e 2013 aumentou nesse grupo indígena a demanda por objetos industrializados, como fogões, freezers e televisores. Os alunos Kalapalo e Pankararu que participaram da elaboração desse trabalho observaram que nas suas experiências pessoais constata-se processo semelhante nas respectivas aldeias no Xingu e em Pernambuco com o estabelecimento do contato oficial, no primeiro caso, e a chegada da energia elétrica, no segundo caso.

Pudemos verificar também que o uso de novas tecnologias pode resultar no esgotamento de recursos naturais, atrapalhando, por exemplo, no caso dos Pankararu, o ciclo reprodutivo dos peixes, pois naquele contexto interferiu no fluxo hidrográfico.

Ainda destacamos o fato observado por Silva (2013) de que há objetos que estão desaparecendo porque os indivíduos mais velhos, entre os Asurini, estão a cada vez em menor quantidade (somente a partir do final dos anos 80 que a situação começou a ser revertida) e/ou os objetos estão sendo substituídos por outros industrializados. 
Nesse tocante, JK observa que também na realidade dos povos no Xingu, segundo seu testemunho e vivência, as mulheres usavam fibra de buriti para colocar polvilho para secar no sol, e agora usam lona ou plástico, objetos que são comprados. Já GP observa que, no cotidiano de seu povo Pankararu, os utensílios de comida eram quase sempre de barro e atualmente eles só utilizam esses materiais nos rituais religiosos, sendo que no dia-a-dia usam plástico, alumínio e vidro, produtos da cultura industrializada. Interesses e influências externos têm feito com que as tecnologias indígenas sofram inovações e/ou recriação de objetos, conforme definição de Silva (2013). Para a autora, a inovação tecnológica é um

[...] fenômeno que compreende a invenção e a adoção. A invenção refere-se ao evento de descoberta e da criação de coisas supostamente não conhecidas previamente (...) A adoção consiste na aceitação e no uso do que foi inventado e, ainda, na adaptação ou apropriação de alguma coisa pré-existente (objetos e/ou técnicas). A inovação tecnológica, portanto, é um processo cultural que implica a dialética entre o novo e o pré existente, a reorganização dos elementos presentes na cultura (material) e a continuidade/ descontinuidade dos princípios socioculturais da produção, utilização e distribuição dos objetos (SILVA, 2013, p. 730).

Ademais, objetos que demandam complexidade na elaboração não têm sido repassados para os mais novos, seja porque demandam mais tempo para aprendizado, e os indivíduos têm cada vez menos tempo, seja porque os indivíduos mais velhos estão em menor quantidade.

De fato, podemos observar, até o presente momento, que há mais pontos negativos que positivos ligados à entrada opulenta dos objetos industrializados nas comunidades. Vemos, por exemplo, como ponto positivo, a possibilidade de aumentar o sistema produtivo, e como pontos negativos, as consequências e os efeitos sobre a saúde, sobre o meio ambiente e o corpo, já que a introdução de novas ferramentas nos processos produtivos produz também alterações nos movimentos corporais empregados nas técnicas, tanto no que se refere ao ritmo quanto à evolução, como também promove alterações nas interações familiares da comunidade. 
Esses relatos correspondem ao que Thiry-Cherques (2006) observa sobre esquema de Bordieu, elaborado em 1977, que leva à análise empírica, é sistêmico, e

deriva do princípio de que a dinâmica social se dá no interior de um /campo/, um segmento do social, cujos/ agentes/, indivíduos e grupos têm /disposições/ específicas, a que ele denomina / habitus/. O campo é delimitado pelos valores ou formas de /capital/ que lhe dão sustentação. A dinâmica social no interior de cada campo é regida pelas lutas em que os agentes procuram manter ou alterar as relações de força e a distribuição das formas de capital específico. Nessas lutas são levadas a efeito/estratégias/ não conscientes, que se fundam no/habitus/ individual e dos grupos em conflito. Os determinantes das condutas individual e coletiva são as/posições/ particulares de todo / agente/ na estrutura de relações. De forma que, em cada campo, o / habitus/, socialmente constituído por embates entre indivíduos e grupos, determina as posições e o conjunto de posições determina o / habitus/ (p. 31).

\section{CONSIDERAÇÕES FINAIS}

Pretendeu-se apresentar uma breve coleta de dados e conhecimentos de alunos indígenas sobre as tecnologias presentes em seus coletivos nas mais diversas atividades do cotidiano. Tratou-se de refletir sobre fenômenos culturais no seu modo físico de apresentação, mas sobretudo focando nas ideias trazidas e elaboradas pelos alunos indígenas e, ao lado deles, explorando a descrição das atividades corriqueiras segundo as narrativas trazidas sobre os processos de desenvolvimento das tecnologias presentes e identificadas nas práticas diárias na aldeia e nos costumes de seus povos. Para enriquecer o breve panorama apresentado, visitouse alguns documentos da literatura nacional e internacional sobre as tecnologias indígenas, com maior detalhamento do panorama encontrado no Brasil. 


\section{REFERÊNCIAS}

GRUPIONI, L. D. B. (2008). Olhar longe, porque o futuro é longe: cultura, escola e professores indígenas no Brasil. Tese de doutorado em Antropologia Social. Departamento de Antropologia da FFLCH/USP. São Paulo: USP. (Tese de Doutorado em Antropologia Social).

INSTITUTO SOCIEDADE, POPULAÇÃO E NATUREZA(2016). Cerratinga: Produção Sustentável e Consumo Consciente. Disponível em: http:// www.cerratinga.org.br/caroa/. Acesso em: nov. 2016.

NEWTON, D. (1986). Cultura Material e História Cultural. Traduzido do original em inglês por Christopher Peterson. In: RIBEIRO, D. et alii. Suma etnológica brasileira. Vol. 2. Tecnologia Indígena. Coord. Berta G. Ribeiro. Fine: Vozes, Petrópolis, 1986.

SANTOS, B. S (org.). (2005). Semear outras soluções: os caminhos da biodiversidade e dos conhecimentos rivais. Rio de Janeiro: Civilização Brasileira.

SANTOS, B. S. (2011). A crítica da razão indolente: contra o desperdício da experiência. Para um novo senso comum: a ciência, o direito e a política na transição paradigmática. São Paulo: Cortez.

SILVA, F. A. (2013). "Tecnologias em transformação: inovação e (re) produção dos objetos entre os Asurini do Xingu”. Bol. Mus. Pára. Emílio Goeldi. Cienc. Hum. Belém, v. 8, n. 3, p. 729-744, 2013. Disponível em: http://www.scielo.br/pdf/bgoeldi/v8n3/14.pdf. Acesso em: Nov. 2016.

RIBEIRO, D. et alii. (1986). Suma etnológica brasileira. Vol. 2. Tecnologia Indígena. Coord. Berta G. Ribeiro. Fine: Vozes, Petrópolis.

THIRY-CHERQUES, H. R. (2016). Pierre Bordieu: a teoria na prática. Disponível em: http://www.scielo.br/pdf/rap/v40n1/v40nla03.pdf . Acesso em: nov. 2016.

VERASZTO, E. V. (2008). "Tecnologia: buscando uma definição para o conceito”. In: PRISMA.com. n. 7. 